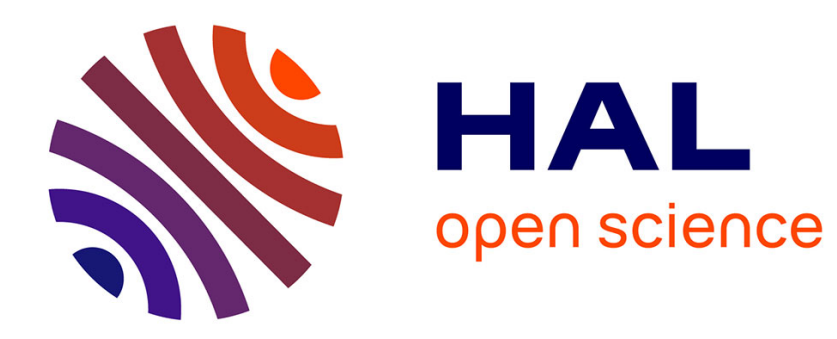

\title{
British Regional Growth and Sectoral Trends - Global and Local Spatial Econometric Approaches
}

Declan Curran

\section{To cite this version:}

Declan Curran. British Regional Growth and Sectoral Trends - Global and Local Spatial Econometric Approaches. Applied Economics, 2011, pp.1. 10.1080/00036846.2011.562170 . hal-00687807

\section{HAL Id: hal-00687807 https://hal.science/hal-00687807}

Submitted on 15 Apr 2012

HAL is a multi-disciplinary open access archive for the deposit and dissemination of scientific research documents, whether they are published or not. The documents may come from teaching and research institutions in France or abroad, or from public or private research centers.
L'archive ouverte pluridisciplinaire HAL, est destinée au dépôt et à la diffusion de documents scientifiques de niveau recherche, publiés ou non, émanant des établissements d'enseignement et de recherche français ou étrangers, des laboratoires publics ou privés. 


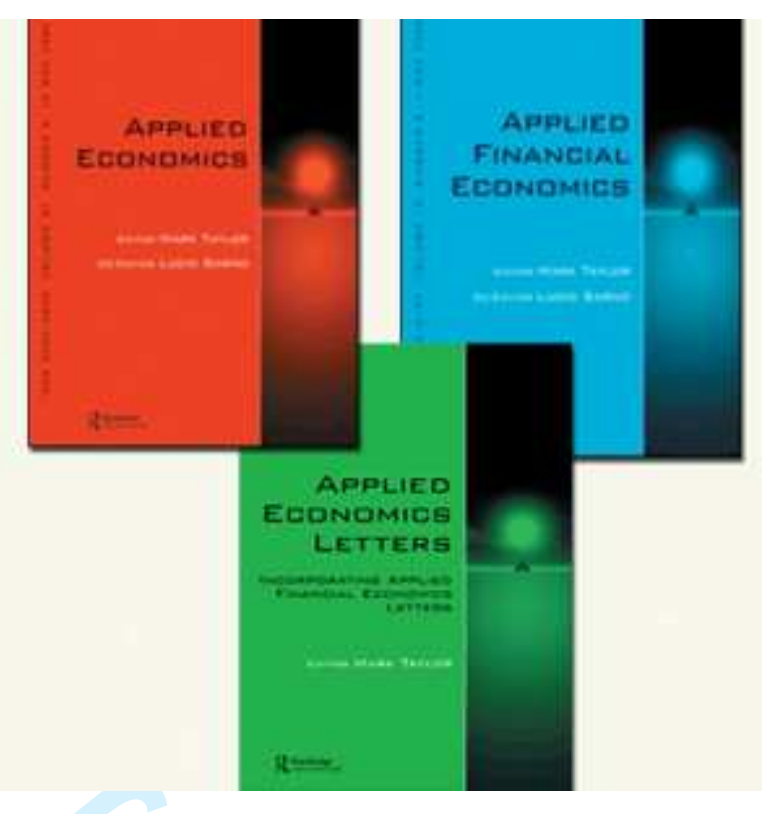

\section{British Regional Growth and Sectoral Trends - Global and Local Spatial Econometric Approaches}

\begin{tabular}{|r|l|}
\hline Journal: & Applied Economics \\
\hline Manuscript ID: & APE-2009-0434.R1 \\
\hline $\begin{array}{r}\text { Journal Selection: } \\
\text { Date Submitted by the } \\
\text { Author: }\end{array}$ & Applied Economics \\
\hline Complete List of Authors: & Curran, Declan \\
\hline JEL Code: & $\begin{array}{l}\text { R12 - Size and Spatial Distributions of Regional Economic Activity } \\
\text { R1 - General Regional Economics < R - Urban, Rural, and Regional } \\
\text { Economics }\end{array}$ \\
\hline Keywords: & $\begin{array}{l}\text { Regional Economic Growth, Britain, Spatial Econometrics, } \\
\text { Convergence }\end{array}$ \\
\hline
\end{tabular}

\section{SCHOLARONE \\ Manuscripts}




\title{
British Regional Growth and Sectoral Trends - Global and Local Spatial Econometric Approaches
}

\author{
Declan Curran \\ Dublin City University Business School \\ Glasnevin \\ Dublin 9 \\ IRELAND \\ Declan.Curran@dcu.ie
}

Revised, December 2010

\begin{abstract}
This paper looks beneath the surface of British sub-regional aggregate GVA growth over the period 1995-2007, by examining how the differing growth dynamics of the secondary and services sectors have influenced the overall regional growth process. A spatial econometric analysis is undertaken which tests regional secondary and services real GVA per capita for absolute and conditional convergence at the NUTS 3 level. Both local and global spatial analysis techniques are utilised in order to gain a detailed insight into the growth process over the period 1995-2007.
\end{abstract}

Keywords: Regional Economic Growth, Britain, Spatial Econometrics

JEL-Classification: R11, R12 


\section{Introduction}

The inherently spatial nature of the economic data underpinning regional economic analysis has received increasing levels of attention in recent years with the emergence of an impressive array of spatial econometric techniques. The impact on the regional growth process of core or peripheral location, proximity to natural resources, and spillover effects from neighbouring regions can now be vividly depicted by means of these techniques. One aspect of this spatial data configuration that has started to attract particular attention is that of spatial heterogeneity across regions: if an economic convergence or divergence process is evident in a given region, does this process exhibit contrasting patterns of spatial association across the sub-regions and does the speed of this convergence (or divergence) process vary at a local level? This issue of heterogeneous spatial relationships has seen spatial analysis move from a global perspective with spatially stable parameters to a local one where economic performance can vary from one sub-region to the next. While global spatial analysis techniques acknowledge the importance of location and proximity in the economic development process by controlling for the influence of spatial autocorrelation, they characterise the underlying process as being spatially stable i.e. the same relationship holds across the entire country. However, agglomeration of economic activity and uneven allocation of resources are common features of regional development. Local spatial analysis techniques offer an opportunity to explore the significance of these spatial disparities.

This paper builds upon the work of Henley (2005), Monastiriotis (2006), and Patacchini and Rice (2007) and employs these global and local spatial techniques to shed light on the regional growth process occurring in Britain over the 1995-2007 period. The analysis undertaken in this paper focuses on NUTS 3 real GVA per capita data spanning from 1995-2007 for the secondary and services sectors. While the time-span (1995-2007) considered in this paper is dictated by data availability, this decade is nonetheless an important one. It captures a period of time where regional growth in many developed countries has been impacted by the move towards the outsourcing of manufacturing and the absorption of phenomenal technological advances. Britain is no exception to this trend: in 2007 primary, secondary, and services as defined in Section 2, below, accounted for approximately $1 \%, 17 \%$ and 


\section{Data Issues and Background}

This paper is primarily focused on NUTS 3 level gross value added (GVA) per capita data. Unadjusted (constrained to headline NUTS2) aggregate GVA by NUTS3 area at current basic prices for the years 1995 to 2007 is available from the Office of National Statistics (www.statistics.gov.uk), as well as being disaggregated for 1) agriculture, hunting and forestry; 2) Industry, which comprises of manufacturing, electricity, gas and water supply, but excludes construction; and 3) service activities, which comprises of business services and finance, as well as distribution, transport and communications (which includes wholesale, retail and hospitality). ${ }^{2}$ These three categories are henceforth referred to as "primary", "secondary", and "services", respectively. Estimates of workplace-based GVA allocate income to the region in which commuters work. Per capita estimates can then be constructed using NUTS 3 level population data available from Nomis Labour Market Statistics (www.nomisweb.co.uk ). The current price GVA DATA has been deflated using the national annual Retail Price Index (RPI) series (rebased to 2007=100). Unfortunately, regional weights for the RPI are only available for the UK for the years 2000, 2003, and 2004. In this study, regional price

\footnotetext{
${ }^{1}$ Calculations based on National Accounts GVA data available from Office of National Statistics Office of National Statistics (www.statistics.gov.uk).

${ }^{2}$ Business services and finance accounted for $52 \%$ of national services GVA in 1995, with distribution, transport and communications accounting for the remaining $48 \%$. By 2007, the corresponding shares were $60 \%$ and $40 \%$ respectively.
} 
level differences have been accounted for the years 1995-99 using 2000 regional RPI weights (UK=100). Similarly for 2001-2002, the 2003 regional RPI weights are used and for 2004-2007 regional RPI weights are used. The basket used to calculate the RPI figures include both consumer goods and services such as household services, personal services, and leisure services. ${ }^{3}$

By way of background, it should be noted that studies of British regional growth patterns over the 1977-1995 period, based on National Accounts GDP per capita data for the 62 British counties and New Earnings Survey data, have identified a number of prominent features. ${ }^{4}$ Chatterji and Dewhurst (1996) conclude that regional GDP per capita data yields no evidence of convergence over this time period, though they do identify some sub-periods that exhibit convergence (in periods where the economy as a whole was experiencing slow growth). Bishop and Gripaios (2004) find no signs of convergence over the 1977-1995 period, regardless of whether one uses National Accounts or New Earnings Survey data. A further insight to emerge from this line of research has been the influence of geographic location and spatial factors on British regional growth. Dewhurst (1998) and Bishop and Gripaios (2004) both find evidence of the influence of a "north-south divide" on British regional growth patterns, which acts to the detriment of the northern areas. More recently a whole range of spatial economic techniques have become available, allowing for a more refined characterisation of the spatial dimension in the regional growth process. When this spatial component is controlled for in convergence analysis, there are signs that not only has Britain not experienced regional convergence in recent decades, but there may even have been a process of divergence in action. Monastiriotis (2006), using wage data from the New Earnings Survey, points to widening aggregate wage disparities throughout the 1980s and 1990s when the issue of spatial dependence is taken into account. Henley (2006) has undertaken a spatial econometric analysis of NUTS 3 level aggregate GVA data for the 1995-2001 period and concludes that British NUTS 3 sub-regions experienced divergence over this time period. The transition from global to local spatial analysis of UK economic activity is evident in the work of Patacchini and Rice (2007). They use local measures of spatial autocorrelation to analyse patterns of spatial association for different indicators of British economic performance. They find that

\footnotetext{
${ }^{3}$ For further details of the composition of the RPI series, see the ONS publication Economic Trends 615, February 2005.

${ }^{4}$ For the purposes of this study, only Great Britain is considered, i.e. Northern Ireland is not included.
} 
the contributions of occupational composition and productivity vary significantly across local regimes, with a 'winner's circle' of areas in the south and east of England benefiting from both above-average levels of productivity and better-than-average occupational composition, while the low-income regime in the north of England suffers from poor occupational composition.

In order to provide a visual impression of the spatial dispersion of real GVA per capita across British NUTS 3 sub-regions, a set of maps are presented (Figures 1-4). Each map is colour coded, with the light shading denoting 0-100\% of median real GVA per capita, medium shading denoting $100-125 \%$, and dark shading denoting over $125 \%$ of median real GVA per capita. Each sub-region is shown relative to the median rather than the mean to mitigate the impact of outliers such as the services GVA of London's financial district located in the Inner London West NUTS 3 sub-region.

Figure 1 presents aggregate real GVA per capita for 1995 and 2007. Salient features include the apparent spatial clustering of high GVA per capita in greater London, Manchester, Liverpool, Edinburgh, Glasgow, and Aberdeen (near the North Sea oil fields); a clear expansion of the greater London high-GVA area over the period in question; increased GVA per capita in Scotland but no consistent GVA per capita increase in Northern England. In comparison, the secondary industry presents a mixed picture (Figure 2): the North of England NUTS 3 sub-regions appear to have experienced mixed fortunes; there are signs of increased secondary GVA per capita in Scotland, while the Midlands and South East exhibit some shuffling of regions between the three categories, but no clear pattern. The business services and finance subsector (Figure 3) and the distribution, transport and communications subsector (Figure 4) highlight the strength of the high-GVA greater London area but continued sluggishness in Northern England and Scotland. In all it would appear that it is the services industry which drives the expansion of the southern high GVA per capita in the aggregate map.

\section{[Insert Figure 1 here]}

[Insert Figure 2 here]

[Insert Figure 3 here]

[Insert Figure 4 here] 
Summary statistics of secondary and services sector real GVA per capita developments over the 19952007 period are provided in Table 1 . The contrast between secondary and services sector GVA per capita developments over the 1995-2004 period is stark. The decrease in the mean, median and standard deviation of secondary GVA per capita over the 13 year period suggest that any convergence experienced in the secondary sector has not been a buoyant one. The GVA per capita of the services sub-sectors, on the other hand, are indicative of healthy growth, with their mean and median showing marked increases over the 13 years.

\section{[Inset Table 1 here]}

In Section 4 a number of additional data sources are drawn upon. Explanatory variables introduced in the conditional convergence analysis of Sub-section 4.3 include average primary school pupil-teacher ratio per county and the average A-level pass rate achieved by pupils in each county, both of which are available from the ONS publication Regional Trends. The number of businesses registered for Value Added Tax and female employment expressed as a proportion of people aged 16+ are both available from Nomis Labour Market Statistics (www.nomisweb.co.uk ). Net capital expenditure data for British sub-regions is available from the ONS series Regions in Figures. ${ }^{5}$

\footnotetext{
${ }^{5}$ Region in Figures has now been discontinued. The final edition was Winter 2004/05 (volume 9). It has now been replaced by a new publication, Regional Snapshot.
} 


\section{Regional Convergence and the Spatial Dimension}

This section begins with a brief description of how $\beta$-convergence analysis, as developed by Baumol (1986), Barro and Sala-I-Martin (1992), and Mankiw et al. (1992), has been augmented to include a number of spatial econometric methods. When considering regional convergence, various empirical approaches have been implemented in the literature: from simple plots of measures of dispersion over time to intra-distributional dynamics using Markov chains applied to GDP per capita. It is $\beta$ convergence analysis, however, that has lent itself most easily to spatial econometric analysis.

\subsection{Global Spatial Econometric Methods and the Modelling of Regional Growth}

While a variety of distinct convergence concepts have emanated from the economic growth literature, one form of convergence which has received particular attention over the last two decades has been that of $\beta$-convergence. This form of convergence occurs when poor regions grow faster than richer regions, resulting in a catching-up process where the poor regions close the economic gap that exists between their richer counterparts. The now-standard specification of $\beta$-convergence can be expressed in vector form as follows:

$$
\ln \left(\frac{y_{t+k}}{y_{t}}\right)=\alpha+\left(1-e^{-\lambda k}\right) \ln \left(y_{t}\right)+\varepsilon_{t}
$$

where $y_{t}$ denotes the vector of per capita income of each state $i$ in year $t ; \alpha$ represents the intercept term, and $\left(1-e^{-\lambda k}\right)$ is the convergence coefficient, which is usually reparametrized as $\beta=\left(1-e^{-\lambda k}\right)$. The $\beta$ coefficient is then estimated using Ordinary Least Squares (OLS), and the speed of convergence, $\lambda$, can then be calculated. A negative estimate for $\beta$ indicates that growth rates of per capita income over the $k$ years is negatively correlated with initial incomes - a finding which is interpreted as a support for the hypothesis of convergence. It is assumed that the error terms from different regions are independent: 


$$
E\left[\varepsilon_{t} \varepsilon_{t}^{\prime}\right]=\sigma_{t}^{2} I
$$

This unconditional $\beta$-convergence specification can then be augmented, as per Barro and Sala-I-Martin (1992), to include a range of control variables (such as differences in human capital accumulation, infrastructure disparities, industrial structure, as well as dummy variables reflecting different regional characteristics) which may capture differences in the paths of steady-state income per capita.

Equations (1) and (2) can be augmented to capture interactions across space, a refinement which reflects more accurately the realities of the growth process across regions. As Henley (2006) notes, this spatial dimension can exert its influence on regional growth through numerous channels: adjustment costs and barriers to labour and capital mobility, spatial patterns in technological diffusion, the ability of regions to pursue independent regional growth policies, and the extent to which neighbouring regions interact and benefit from spillover effects. Following from Anselin (1988), spatial dependence has been incorporated into the $\beta$-convergence specification in two ways: (i) as an explanatory variable in the specification or (ii) as operating through the error process. ${ }^{6}$ The former, known as a Spatial Autoregressive Model (SAR), depicts a region's growth as being directly affected by growth in neighbouring regions. This direct spatial effect is independent of the exogenous variables and is captured by including a spatial autoregressive parameter, $\rho$, and a spatial weight matrix, $W$, in the specification:

$$
\ln \left(\frac{y_{i, t+k}}{y_{i, t}}\right)=\alpha+\left(1-e^{-\lambda k}\right) \ln \left(y_{i, t}\right)+\rho W \ln \left(\frac{y_{i, t+k}}{y_{i, t}}\right)+\varepsilon_{i, t}
$$

In equation (3), the growth of a given region is influenced by the growth rate of adjacent regions. However, it may be the case that rather being directly affected by the growth rate of its neighbours, a region's growth rate may be influenced by a complex set of random, unexpected shocks transmitted across space arising from spillovers associated with technology or consumer tastes. In this Spatial Error Model (SEM) case, the spatial influence does not enter the systematic component of the

\footnotetext{
${ }^{6}$ For more detailed treatment of spatial autoregressive and spatial error models, see Bernat (1996), Rey and Montouri (1999), and Fingleton and Lopez-Bazo (2006).
} 


$$
\ln \left(\frac{y_{i, t+k}}{y_{i, t}}\right)=\alpha+\left(1-e^{-\lambda k}\right) \ln \left(y_{i, t}\right)+\varepsilon_{i, t} \quad \text { where } \quad \varepsilon_{i, t}=\zeta W \varepsilon_{i, t}+u_{i, t}
$$

specification. Instead, it is captured in an error term which contains a spatial error coefficient, $\zeta$, and an idiosyncratic component, $u$, where $u \sim N\left(0, \sigma^{2} I\right)$.

\section{Section 4 reports results for cross-sectional growth equation regressions which test for absolute and conditional convergence using the SAR and SEM specifications.}

\subsection{Local Spatial Econometric Methods}

As Eckey et al. (2007) note, the influence between the dependant variable and a set of independent variables often differs across regions (spatial non-stationarity). Therefore it may be desirable to utilise an econometric technique which takes account of the possibility of spatial heterogeneity in speeds of convergence across regions. One such technique is geographically weighted regression (GWR), a technique for exploratory spatial data analysis developed by Fotheringham, Brunsdon, and Charlton, (see, for example Brunsdon et al. (1996, 1998), Fotheringham et al. (1998, 2002). GWR permits parameter estimates to vary locally as the parameters are estimated separately at each observed location. The standard OLS regression specification of (1) above can be rewritten as follows to incorporate parameters that vary locally:

$$
\ln \left(\frac{y_{i, t+k}}{y_{i, t}}\right)=\alpha_{i}+\sum \beta_{i} \ln \left(y_{i, t}\right)+\varepsilon_{i, t}
$$

where, as discussed above, $\beta_{i}=\left(1-e^{-\lambda_{i} k}\right)$. In the calibration, observations are weighted according to their proximity to region $i$. As the distance between two regions becomes smaller, the weight becomes greater. The Euclidian distance between to regions $\left(d_{i j}\right)$ is used to calculate a Gaussian weighting function. At the observed point, $i$, the weighting of the data point will be unity and the weighting of 
the other data will decrease according to a Gaussian curve as the distance between $i$ and $j$ increases, so that for a data far away from $i$ the weighting will fall close to zero, effectively excluding these observations from the estimation of parameters for location $i$; Fotheringham et al. (2002). ${ }^{7}$

$$
w_{i j}=e^{-0.5 \cdot\left(d_{i j} / b\right)^{2}}
$$

Similar to kernel regression estimation, it is the bandwidth, $b$, that determines the extent to which the distances are weighted. A greater bandwidth increases the smoothing across the regions, giving regions $\mathrm{i}$ and $\mathrm{j}$ a relatively larger (smaller) weighting if they are far from (close to) each other. The bandwidth is computed by minimising the Akaike information criteria. In the GWR setting, the parameter estimate for $\beta_{i}$ can then be estimated by weighted least squares, with the values of the independent variables from regions near to region $i$ having a greater influence as they are multiplied by region $i$ 's weighting matrix, $\mathbf{W}_{i}$ :

$$
\hat{\beta}_{i}=\left(X^{\prime} \cdot W_{i} \cdot X\right)^{-1} \cdot X^{\prime} \cdot W_{i} \cdot Y
$$

where $\mathbf{X}$ is the matrix form of the independent variable $\ln \left(y_{i, t}\right)$ and $\mathbf{Y}$ is the matrix form of the $\ln \left(\frac{y_{i, t+k}}{y_{i, t}}\right)$ dependant variable.

However GWR is not without its pitfalls. Wheeler (2009) notes that empirical research and simulation studies have demonstrated that local correlation in explanatory variables can lead to estimated regression coefficients in GWR that are strongly correlated. The standard error calculations in GWR are only approximate due to reuse of the data for estimation at multiple locations (Lesage, 2004) and due to using the data to estimate both the kernel bandwidth and the regression coefficients (Wheeler and Calder, 2007). An issue related to inference of the regression coefficients is that of multiple testing in GWR, where tests of coefficient significance are carried out at many locations using the same data (Wheeler, 2007; Fotheringham et al., 2002). Following Ord and Getis (1995) a Bonferroni correction procedure is used to adjust the significance level of individual tests, where the overall significance

\footnotetext{
${ }^{7}$ A bi-square (adaptive) kernel Gaussian kernel has been used in the GWR specifications presented in the forthcoming sections.
} 
level is adjusted by dividing by the number of observations in the sample (i.e the number of multiple tests) to get the individual significance level for each observation.

\section{Spatial Analysis of $\beta$-convergence}

The focus now turns to establishing the empirics of regional growth and $\beta$-convergence across British sub-regions, in the presence of possible spatial dependence. The first step is to statistically test for the presence of spatial autocorrelation in sub-regional secondary, services and aggregate real GVA per capita data using the well-known diagnostic for global spatial autocorrelation, Moran's $I$ statistic. Once the presence of spatial autocorrelation has been established, the issue of convergence across subregions is then considered by augmenting the cross-sectional growth equations which test the hypotheses of absolute conditional convergence to incorporate spatial autoregressive (SAR) components and spatial error (SEM) components, as well as the local GWR specification.

\subsection{Diagnostic Test for Global Spatial Autocorrelation}

The Moran's I statistic for spatial autocorrelation yields a test statistic which can be defined as follows:

$$
I_{t}=\left(\frac{n}{s}\right) \frac{\sum_{i=1}^{n} \sum_{j=1}^{n} w_{i j} y_{i t} y_{j t}}{\sum_{i=1}^{n} \sum_{j=1}^{n} y_{i t}^{2}}
$$

where $w_{i j}$ represents the elements of the spatial weighting matrix $W, n$ and $s$ denote the total number of sub-regions and the summation of $w_{i j}$ respectively. The results of this diagnostic test for spatial autocorrelation on secondary, services and aggregate log real GVA per capita for 1995 and 2007, as well as for real GVA per capita growth over the 1995-2007 period, are reported in Table 2.

The test has been carried out using two different types of spatial weighting matrix: i) an inverse distance spatial weighting matrix, where $w_{i j}$ denotes the row standardized reciprocal distance between sub-regions $i$ and $j$; and ii) a fixed distance binary contiguity matrix, where $w_{i j}=1$ if sub-regions are geographically adjacent with a given distance threshold and and $w_{i j}=0$ for sub-regions outside of the threshold. The fixed distance threshold (140km) for NUTS 3 level secondary and services real GVA 
per capita has been selected using multi-distance spatial cluster analysis (Ripley's k-function). Ripley's k-function is a descriptive statistic used for detecting deviations from spatial homogeneity by comparing, over different geographic intervals, the mean and variance of the spatial distribution of the actual data with those generated by a homogenous Poisson process; Dixon(2002). The fixed distance threshold is chosen as the distance within which deviations from spatial homogeneity are observed to highest. As this spatial weight specification is intuitive and derived from the underlying data, it used in the regression analysis undertaken in the following sub-section.

\section{[Insert Table 2 here]}

It is clear from Table 2 that secondary, services, and aggregate real GVA per capita do indeed exhibit strong spatial autocorrelation across sub-regions in both 1995 and 2007. However, when one considers growth rates over the 1995-2004 period, secondary real GVA per capita growth exhibits spatial autocorrelation within the $140 \mathrm{~km}$ threshold when the spatial weight specification is binary contiguous, while neither business services and finance nor distribution, transport and communications growth display spatial autocorrelation in this setting. This absence of spatial autocorrelation in real GVA per capita growth of these services subsectors is in keeping with the visual impression provided by Figure 4, in which the London-centric spatial pattern of real GVA per capita appears to be firmly established prior to 1995 and virtually unchanged over the 1995-2007 period.

\subsection{Global Analysis of Absolute $\beta$-convergence}

Table 3 below presents spatial autoregressive (SAR) and spatial error and (SEM) cross-sectional regressions of secondary, services, and aggregate GVA per capita growth on initial, 1995, log GVA per capita $\left(\ln G V A_{1995}\right)$, as outlined in Section 3. GVA per capita data for 125 of the 128 NUT 3 subregions are used in the specifications in Table $3 .^{8}$ In keeping with the notation of Section 3, $\rho$ and $\tau$

\footnotetext{
${ }^{8}$ In order to ensure consistency with the explanatory variables included in Table 4, the NUTS 3 sub-regions of East and West Cumbria have been amalgamated to form Cumbria. Similarly, East Derbyshire and South and West Derbyshire have been combined to form Derbyshire, while North and South Nottinghamshire have been combined to form Nottinghamshire.
} 
represent the spatial autocorrelation coefficient and spatial error coefficient, respectively. The spatial weighting matrix used in throughout this section is the row standardised inverse distance matrix.

\section{[Insert Table 3 here]}

From Table 3 it is clear that secondary sector GVA per capita growth exhibits convergence over the 1995-2007 period, with an estimated annual speed of convergence ranging from $0.8 \%-1.03 \%{ }^{9}$ Of the two services sub-sectors under consideration, business services and finance exhibits neither convergence nor divergence over the period in question. Distribution, transport and communications, does experience convergence in the growth of its real GVA per capita over the 1995-2007 period, with an annual convergence speed of approximately $1.2 \%$. As for the competing spatial specifications, in the case of the secondary sector and business services and finance and both yield similar $\mathrm{R}^{2}$ values and log-likelihood values, while the SEM specification yields a noticeably higher $\mathrm{R}^{2}$ value for distribution, transport and communications. It should also be noted that the SAR spatial autocorrelation estimate is significant in the case the secondary and distribution, transport and communications sectors, while the SEM spatial error estimate is significant only in the secondary sector.

\subsection{Global Analysis of Conditional $\beta$-convergence}

The cross-sectional specifications used to test for absolute convergence are now augmented with a set of explanatory variables, which may capture differences in the paths of steady-state GVA per capita. Foremost amongst these are initial education levels and human capital formation, which are necessary to raise productivity. ${ }^{10}$ Following Henley (2005), two variables are utilised here to capture distinct aspects of human capital accumulation process: (i) the county average primary school pupil-teacher ratio (Pupil_Teacher) and (ii) the average A-level pass rate (grades) achieved by pupils in each county. It is this exam which enables pupils to enter university. As 1995 data is unavailable for these variables, data dating from 1993 is used instead. As these variables are unavailable at sub-regional

\footnotetext{
${ }^{9}$ As the dependent variable is defined as average real GVA per capita growth for 1995-2004, the speed of convergence, $\theta$, is calculated as $\theta=\log (1-\beta \mathrm{k}) / \mathrm{k}$, where $\mathrm{k}$ denotes the number of years in the time period.

${ }^{10}$ See Mankiw et al. (1992) and Barro and Sala-I-Martin (1995, pp. 420-445) for a detailed discussion regarding the inclusion of control and environmental variables in conditional convergence regressions.
} 
level, the data for each county is applied to the sub-region residing in that county. As discussed in Section 2, location and geographic proximity have been identified as key drivers of the British regional growth process. In order to capture this, a set of dummy variables for the eleven NUTS 1 regions has been constructed. Furthermore, the rural/urban orientation of each sub-region is captured through the inclusion of a variable representing each sub-region's 1995 agricultural real GVA as a proportion of aggregate real GVA (Agri). Data on the capital stock residing in each sub-region at the start of the 1995-2007 period is unavailable. Instead, as per Hart and McGuinness (2003), the number of businesses registered for Value Added Tax (VAT) disaggregated for secondary and services sectors is used as a proxy for capital utilization. This variable (No. of Businesses) is expressed in per capita terms with respect to the relevant sub-region. In order to control for capital investment, net capital expenditure as a proportion of aggregate real GVA for each sub-region (Capital Expenditure) in 1997, deflated as described in Section 2, is also included in the specifications. ${ }^{11}$ As per Perugini and Signorelli (2004), a further control variables, females in employment in 1995 expressed as a proportion of people aged 16+ (Fem Emp'ment), is included in order capture differences in local labour market conditions (such as the tightness of the labour market) at the beginning of the 19952007 period. From a methodological perspective, one weakness of cross-region regressions is that of reverse causality and endogeneity. With the exception of Capital Expenditure, all the explanatory variables used in the conditional convergence specifications refer to 1995 or earlier - and thereby not susceptible to such reverse causality. Capital Expenditure is assumed to be weakly exogenous, and instrumental variable techniques have not been applied to it.

Similar to the absolute convergence case, the results reported in Table 4 are indicative of secondary sector convergence and exhibit a similar estimated annual speed of convergence (1.1\%-1.3\%). Of the services sub-sectors, distribution, transport and communications once again exhibits a convergence tendency over the 1995-2007 period, with an estimated convergence speed in a range of $1.5 \%-1.6 \%$. Business services and finance does not exhibit a tendency towards either convergence or divergence in this case. In these conditional convergence specifications, the SEM spatial error estimate is significant across the secondary and services sectors while the SAR spatial autocorrelation estimate is only

\footnotetext{
${ }^{11}$ Capital expenditure data for the 11 NUTS 3 regions of Wales was unavailable for 1997. As a proxy, the capital expenditure per worker figure for the NUTS 1 region, Wales, is weighted by the real GVA of NUTS 3 region.
} 
significant for business services and finance. Furthermore, the secondary sector SEM estimate exhibits a positive sign while the services subsector SEM and SAR estimates both carry negative signs. This may be indicative of differing mechanisms through which secondary and services sectors spill over to adjoining NUTS 3 areas, with services centres being more geographically bounded.

\section{[Inset Table 4 here]}

The conditional convergence regressions also provide some insights into the factors which have driven these growth trends over the 1995-2004 period. In the secondary sector, the SAR and SEM specifications point to the average primary school pupil-teacher ratio (Pupil_Teacher) as positively influencing secondary sector real GVA per capita growth over the period in question. In the SAR specification, the Scotland regional dummy also appears to exert a positive significant impact on secondary sector real GVA per capita growth between 1995 and 2007. The set of explanatory variables possess less explanatory power in the case of business services and finance than for the secondary sector or distribution, transport and communications. Nonetheless the business services and finance regression indicates that both the average primary school pupil-teacher ratio (Pupil_Teacher) and the Scotland regional dummy once again positively influence real GVA per capita growth in that services subsector. Across the distribution, transport and communications SAR and SEM regression specifications, the significant positive Fem Emp'ment coefficient indicates that the local labour market conditions positively impacted growth over the period in question. The positive significant $N o$. of Businesses (in the SEM specification) and the negative significant Agri variable are indicative of the urban orientation of distribution, transport and communications real GVA per capita growth. ${ }^{12}$

\footnotetext{
${ }^{12}$ Two problems often emerge in studies utilising highly disaggregated regional data: (i) neglect of the impact of commuter flows and (ii) the administrative delineation of regions may not reflect self-contained economic areas. See Fingelton (2003) and Curran (2009) for a discussion of these issues in the British context.
} 


\subsection{Local Analysis of Conditional $\beta$-convergence}

The geographically weighted regression technique (GWR) is now utilised to undertake a local analysis of conditional $\beta$-convergence on the British NUTS 3 1995-2007 real GVA per capita data. The GWR procedure is used to estimate the local parameter values of cross-sectional regressions of secondary, business services and finance, and distribution, transport and communications GVA per capita growth on initial secondary and services $\log$ GVA per capita $\left(\ln G V A_{1995}\right)$ and the set of explanatory variables described above. The regional dummy variables are omitted from the GWR specification. Tables 5-7 below present the minimum, lower quartile, median, upper quartile, and maximum values of the set of local parameter value estimates and $\mathrm{R}^{2}$. For comparison, the global SAR and SEM estimates from Table 4 are also are also presented. Significance levels for the global SAR and SEM estimates are indicated in Tables 5-7, while significance levels for the variables we are most interested in (the significant secondary and distribution, transport and communications $\operatorname{lnGVA}_{1995}$ estimates) are presented via colour-coded maps in Figures 5 and 6.

\section{[Inset Table 5 here] \\ [Insert Table 6 here] \\ [Insert Table 7 here]}

When the secondary sector and both services sub-sector local GWR parameter estimates for $\ln G V A_{1995}$ are compared with those of the global SAR and SEM specifications, they appear to be in the same order of magnitude and display the same sign (Tables 5-7). As with the global SAR and SEM parameter estimates, secondary sector and distribution, transport and communications sub-sector real GVA growth per capita over the 1995-2007 period exhibits convergence, while business services and finance does not exhibit any tendency towards convergence or divergence.

An inspection of the statistical significance of the local parameter estimates of secondary sector and transport and communications sub-sector $\ln G V A_{1995}$ is presented in Figure 5, with the Bonferroni significance level $(0.04 \%)$, as well as the $5 \%, 1 \%$, and $0.5 \%$ significance levels illustrated. It is clear from Figure 5 that the secondary sector GWR specification yields $\ln G V A_{1995}$ parameters statistically 
significant only at $5 \%$ or $1 \%$ significance levels in the Scottish NUTS 3 regions. This finding, which was anticipated by the significant Scotland regional dummy variable in the SAR specifications of Table 4, may be reflecting Scotland's success in the 1990s in attracting multinational computer hardware manufacturers; van Egeraat and Jacobson (2004). However, as these computer hardware activities began to shift towards Eastern Europe in the early 2000s, any associated convergence trends may have been transitory.

The local $\ln G V A_{1995}$ parameter for distribution, transport and communications sub-sector, on the other hand, is statistically significant across the entire country and displays highest statistical significance in peripheral western and northern regions. A similar trend is evident in Figure 6, which illustrates the speed of secondary sector and distribution, transport and communications sub-sector convergence indicated by the local $\ln G V A_{1995}$ parameters. While the secondary sector exhibits an annual convergence speed of $1 \%-1.5 \%$ in Scotland only, the distribution, transport and communications sub-sector yields convergence speeds of $1-1.5 \%$ per annum in the South East, but reside within a range of $1.5 \%-2 \%$ per annum across the rest of Britain.

\section{[Insert Figure 5 here]}

\section{[Insert Figure 6 here]}

\section{Conclusions}

This paper addresses the following question: how should the process of British regional economic growth over the decade 1995-2007 be characterised? Disaggregating British real GVA per capita into its secondary and services components indicates it is an oversimplification to characterize the development process experienced in this time period as a convergence process. While economic growth in the secondary sector and in certain services activities may well have manifested itself in a convergent regional growth process, at the same time growth in services activities such as business 
services and finance appears to follow a very persistent spatial pattern that has been established prior to 1995 and has been reinforced over the subsequent years.

While global spatial regression techniques acknowledge the importance of location and proximity in the economic development process by controlling for the influence of spatial autocorrelation, they characterise the underlying process as being spatially stable i.e. the same relationship holds across the entire country. Even a cursory glance at the spatial dispersion of British services sector real GVA per capita over the 1995-2007 period suggests that such a characterisation is unlikely to reflect actual services sector development. What is more, the growing contribution of services sector GVA to the aggregate GVA suggests that this issue is not confined to the services sector development process.

The main findings of this paper concerning the unevenness of real GVA per capita convergence across the secondary and services sectors are evident from both global and local spatial analysis. Once these trends are established at a global level, the local spatial analysis techniques then provide additional insights as how these trends play out "on the ground". In this way, employing global and local spatial analysis in a complementary fashion facilitates a more detailed characterisation of the British economic development process over time.

\section{References}

Anselin L. (1988) Spatial Econometrics: Methods and Models, Kluwert Academic.

Barro R. J. (1991) Economic Growth in a Cross-Section of Countries, Quarterly Journal of Economics $105,407-443$.

Baumol WJ (1986) Productivity Growth, Convergence, and Welfare: What the Long-run Data Show, American Economic Review 76: 1072-1085.

Bernat A. (1996) Does Manufacturing Matter? A Spatial Econometric View of Kaldor's Laws, Journal of Regional Science 36: 463-477. 
Bishop P. and P. Gripaios (2004), Earnings Biases and Convergence in the UK: A County Level Analysis, Applied Economics Letters 11(1), 33-37.

Bishop P. and P. Gripaios (2006) Earnings Convergence in GB Counties: A Distribution Dynamics Approach, Applied Economics Letters 13, 29-33.

Brunsdon, C., Fotheringham, A. S. and M. E. Charlton (1996) Geographically Weighted Regression: A Method for Exploring Spatial Nonstationarity, Geographical Analysis , 28, 281-298.

Brunsdon, C., Fotheringham, A. S. and M. E. Charlton (1998) Spatial Nonstationarity and Autoregressive models, Environment and Planning A, 30, 957-973.

Chatterji, M. and J. H. L Dewhurst (1996) Convergence Clubs and Relative Economic Performance in Great Britain: 1977-1991, Regional Studies, 30, 31-40.

Colavecchio, R., Curran D., and M.Funke (2009) Drifting Together or Falling Apart? The Empirics of Regional Economic Growth in Post-Unification Germany, Applied Economics (forthcoming).

Curran D. (2009) “British Regional Economic Growth: A Spatial Econometric Approach”, European Journal of Spatial Development, Refereed Paper No. 37.

Dewhurst J. (1998) Convergence and Divergence in Regional Household Incomes per Head in the United Kingdom, 1984-93, Applied Economics 30, 31-35.

Dixon P. (2002) Ripley's K-function. In: El-Shaarawi AH, Piergorsch WW (eds) Encyclopedia of Environmetrics, 3, 1976-1803 John Wiley \& Sons, New York, USA. 
Egeraat, C. van, and D. Jacobson (2004) The Rise and Demise of the Irish and Scottish Computer Hardware Industry, European Planning Studies, 12, 6, 800-834.

Eckey, H-F., Kosfeld, R., and M. Türck (2007) Regional Convergence in Germany: a Geographically Weighted Regression Approach, Spatial Economic Analysis,2:1,45-64

Fingleton B. (2003) Increasing returns: evidence from local wage rates in Great Britain Oxford Economic Papers.55: 716-739

Fingleton B. and E. Lopez-Bazo (2006) Empirical Growth Models with Spatial Effects, Papers in Regional Economic Science 85(2)

Fotheringham, A. S., Brunsdon, C. and M. E. Charlton (2002) Geographically Weighted Regression. The Analysis of Spatial Varying Relationships, Chichester, Wiley.

Fotheringham, A. S., Charlton, M. E. and C. Brunsdon (1998) Geographically Weighted Regression: A Natural Evolution of the Expansion Method for Spatial Data Analysis, Environment and Planning, $30,1905-1927$.

Hart M. and S. McGuinness (2003) Small Firm Growth in the UK Regions 1994-1997: Towards an Explanatory Framework, Regional Studies 37(2): 109-122

Henley, A. (2005) On Regional Growth Convergence in Great Britain, Regional Studies 39, 12451260

LeSage J. P. (2004) A Family of Geographically Weighted Regression Models" Advances in Spatial Econometrics, Methodology, Tools and Applications Eds L Anselin, R J G M Florax, S J Rey (Springer Verlag, Berlin) $241-264$. 
Mankiw G, Romer D. and D. Weil (1992) A Contribution to the Empirics of Economic Growth, Quarterly Journal of Economics 107: 407-437.

\begin{abstract}
Monastiriotis, V. (2006) Sub-regional Disparities in Britain: Convergence, Asymmetries and Spatial Dependence, Research Papers in Environmental and Spatial Analysis No. 12, European Institute, London School of Economics.
\end{abstract}

Ord J. K. and A. Getis (1995) Local spatial autocorrelation statistics; distributional issues and an application, Geographical Analysis 27, 286-305.

Patacchini, E. and P. Rice (2007) Geography and Economic Performance: Exploratory Spatial Data Analysis for Great Britain, Regional Studies, 41:4,489-508

Perugini,C. and M. Signorelli (2004) Employment Performance and Convergence in the European Countries and Regions, The European Journal of Comparative Economics Vol. 1, n. 2, 243-278.

Rey S. and B. Montouri (1999) U.S. Regional Income Convergence: A spatial Econometric Perspective, Regional Studies 33: 143-156.

Wheeler, D., and Calder C. (2007) An Assessment of Coefficient Accuracy in Linear Regression Models with Spatially Varying Coefficients, Journal of Geographical Systems 9(2) 145 - 166

Wheeler D. (2009) Simultaneous Coefficient Penalization and Model Selection in Geographically Weighted Regression: The Geographically Weighted Lasso, Environment and Planning A 41, 722-742 


\section{Acknowledgements}

The author wishes to acknowledge the support of the Irish Social Sciences Platform (ISSP) and the National Institute for Spatial and Regional Analysis (NIRSA). The author also wishes to thank Stewart Fotheringham for helpful comments on an earlier draft. 
Figure 1: Aggregate Real GVA per Capita (2007£), 1995 (left) and 2007 (right)
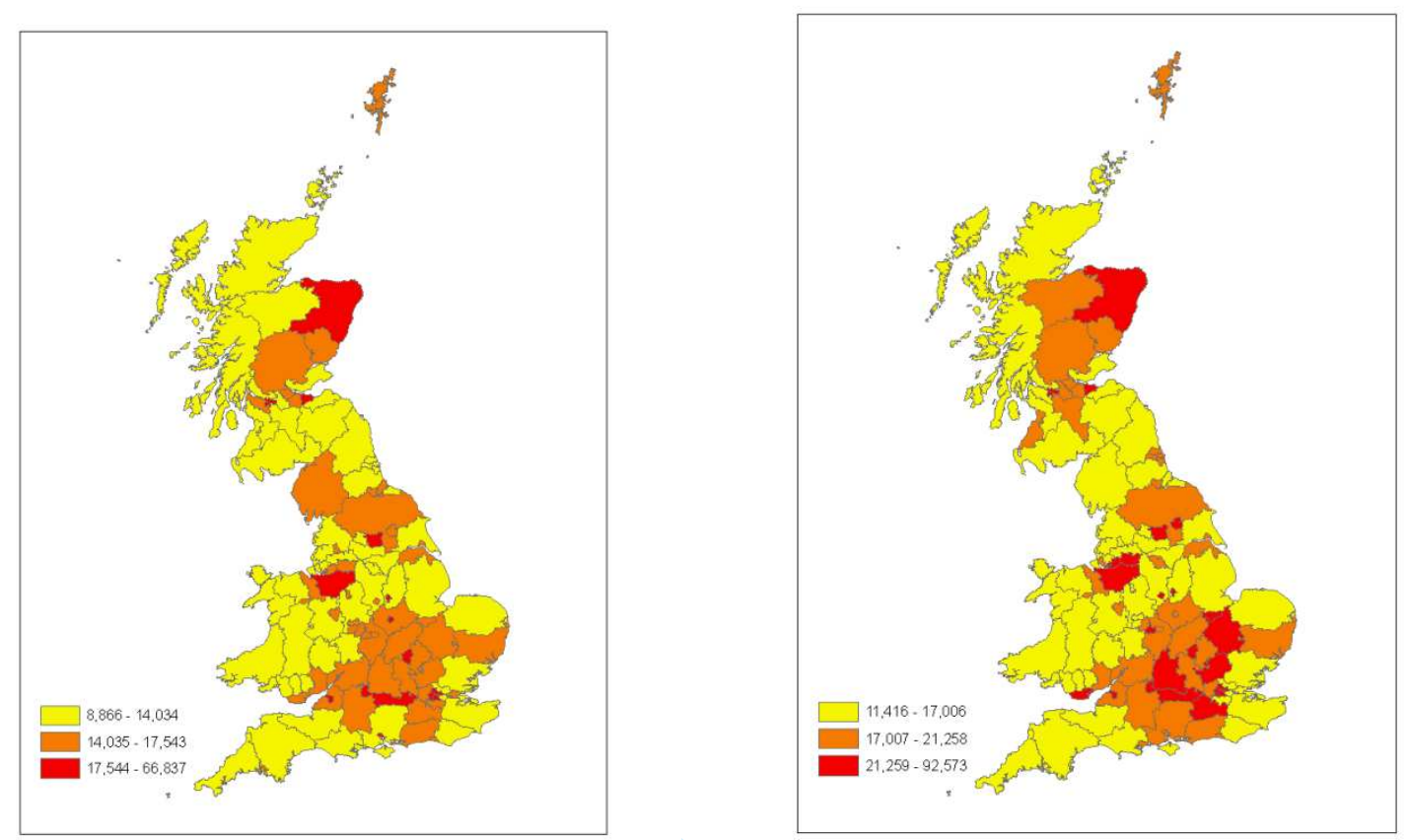

Figure 2: Secondary Sector Real GVA per Capita (2007£), 1995 (left) and 2007(right)
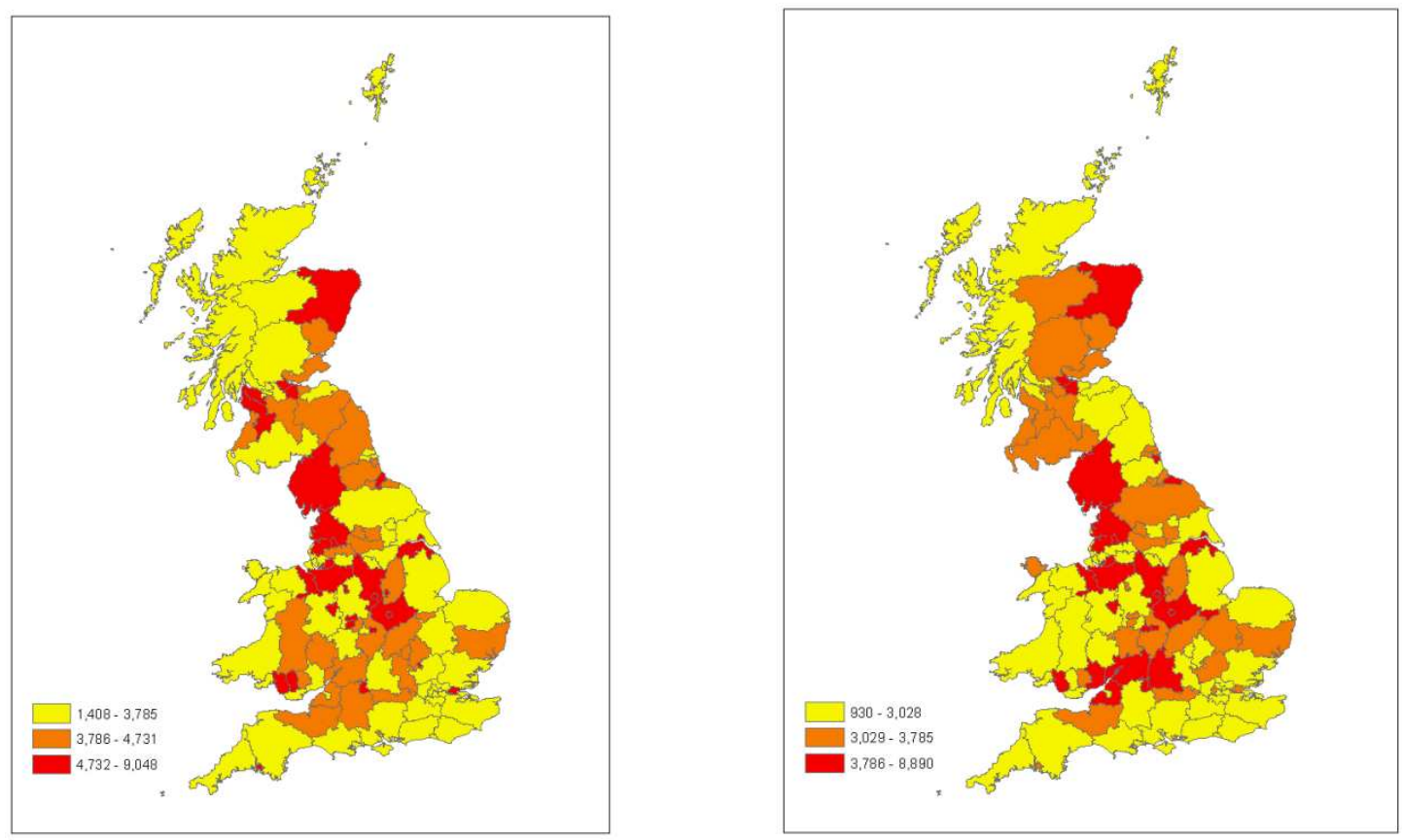

Editorial Office, Dept of Economics, Warwick University, Coventry CV4 7AL, UK 
Figure 3: Business Services and Finance GVA per Capita (2007£), 1995 (left) and 2007 (right)
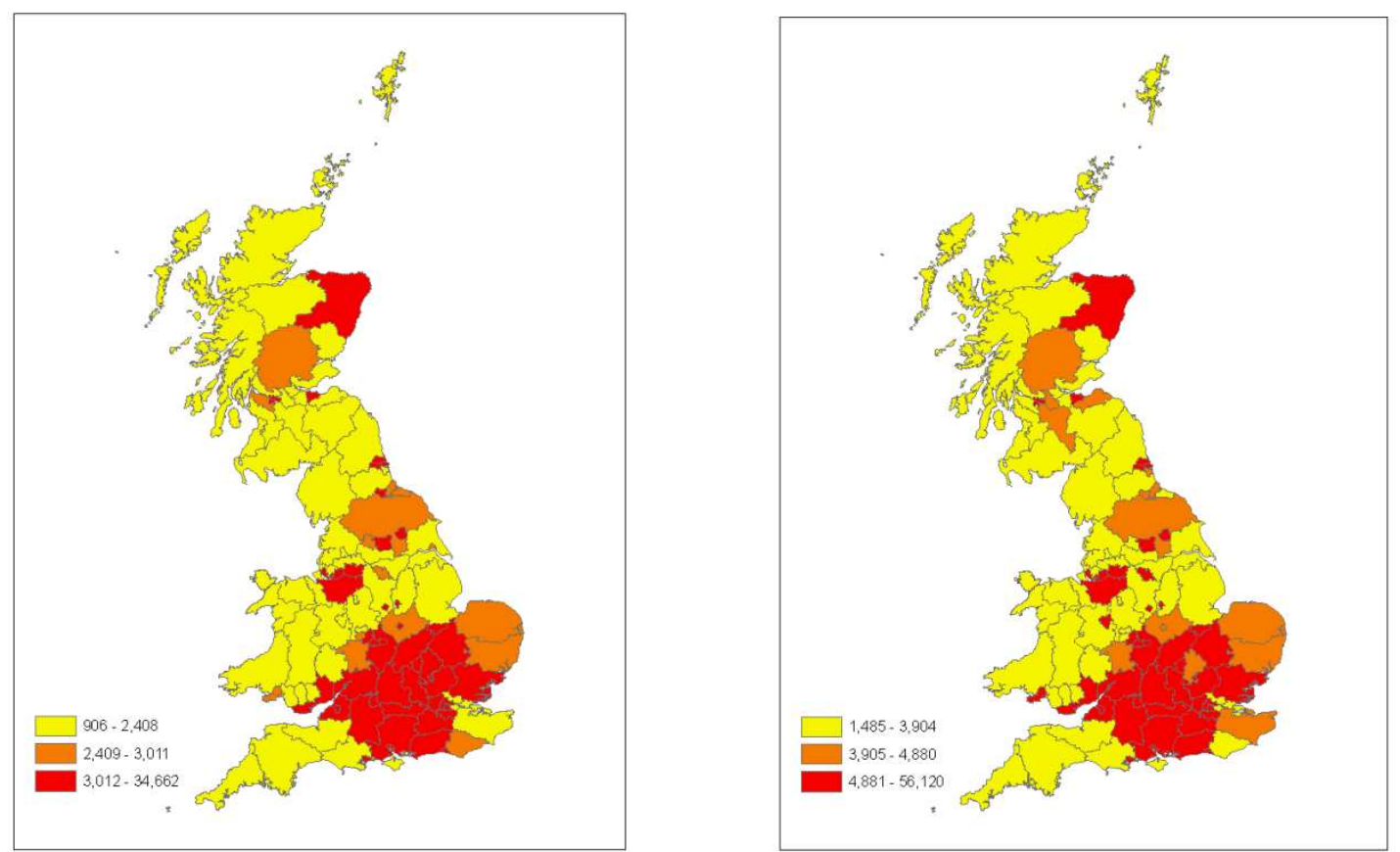

Figure 4: Distribution, transport and communications GVA per Capita (2007£), 1995 (left) and 2007 (right)
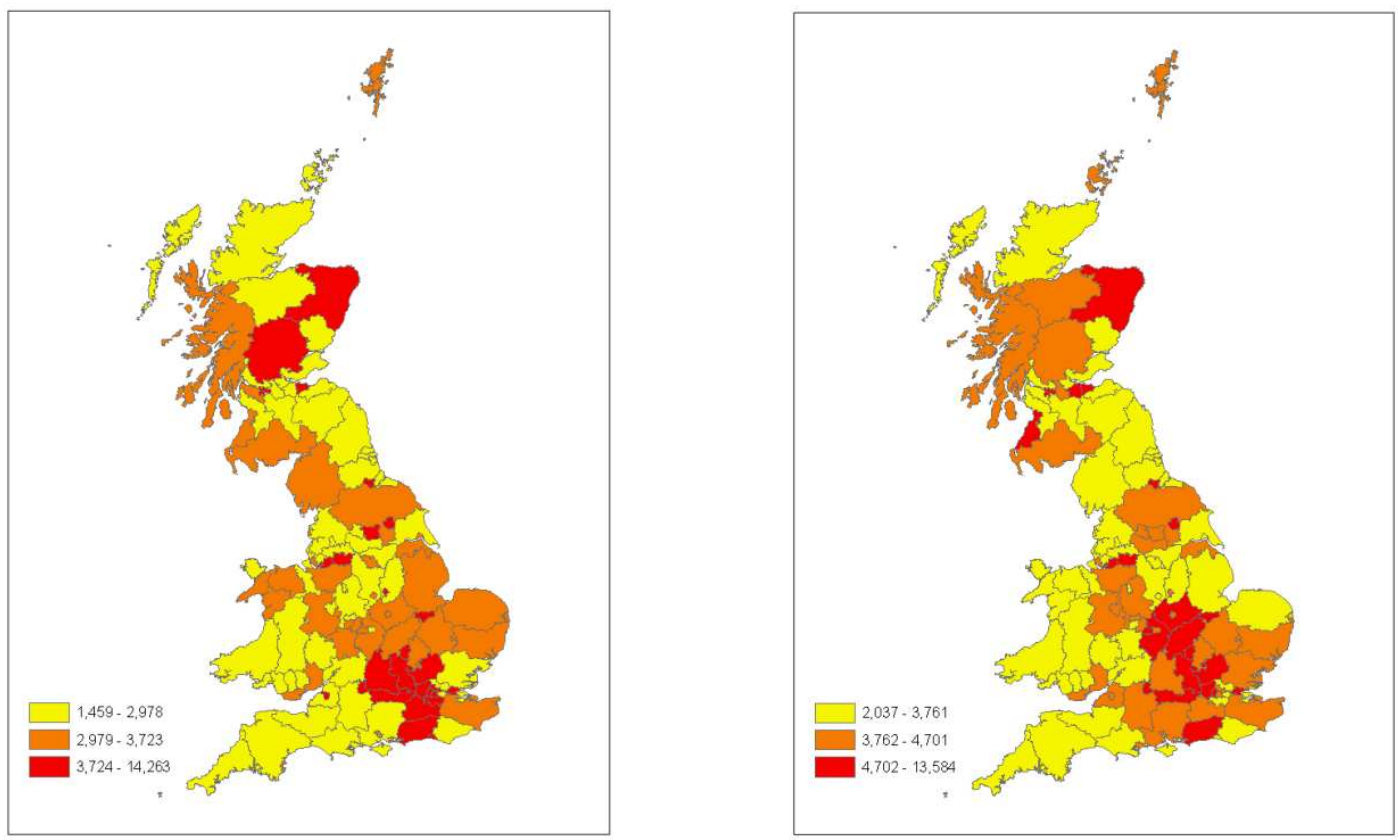

Editorial Office, Dept of Economics, Warwick University, Coventry CV4 7AL, UK 
Figure 5: Local $t$-statistics for 1995 logged secondary real GVA per capita (left) and distribution, transport and communications GVA Per Capita (right) GWR parameter estimates
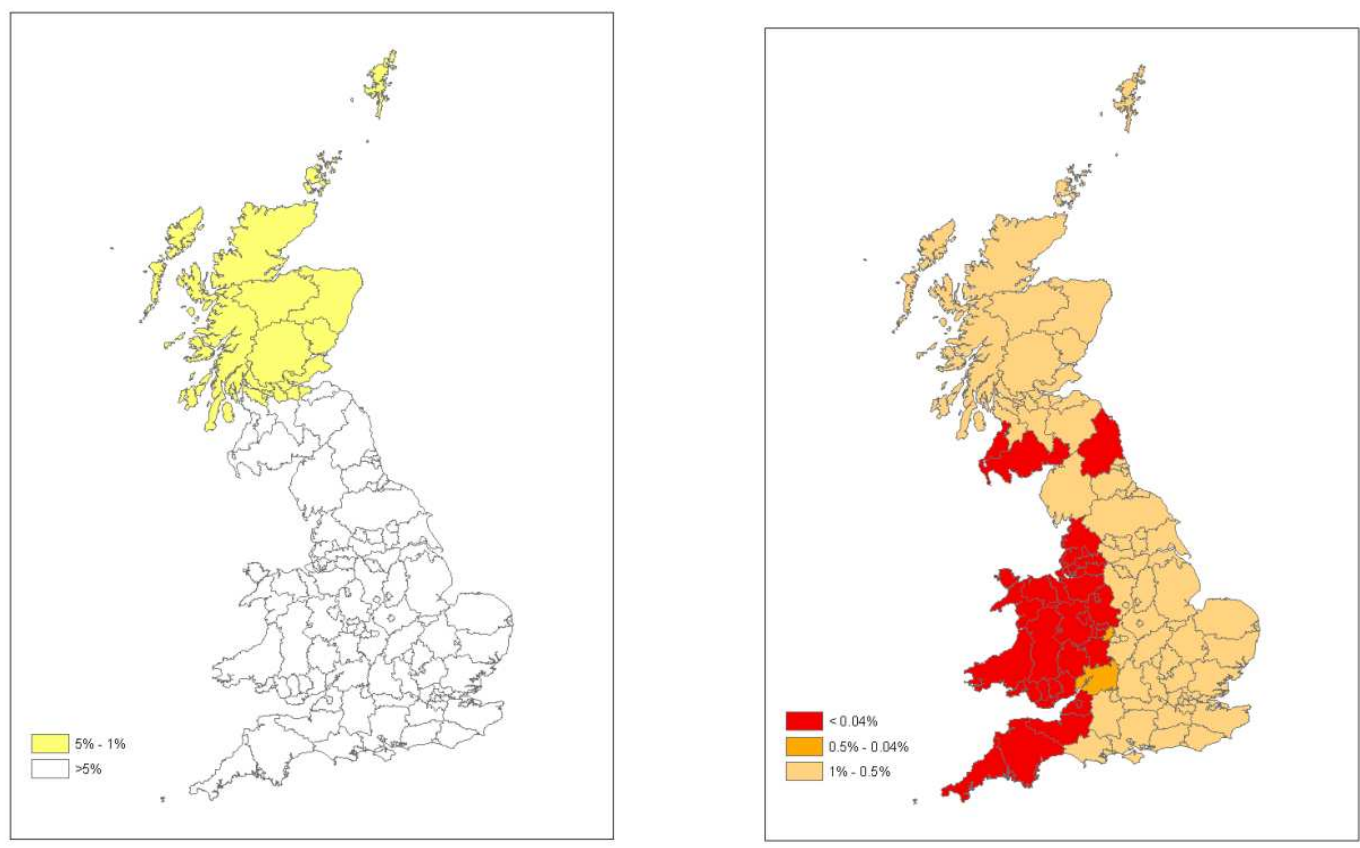

Figure 6: Convergence speeds based on 1995 logged secondary real GVA per capita (left) and distribution, transport and communications GVA Per Capita (right) GWR parameter estimates 

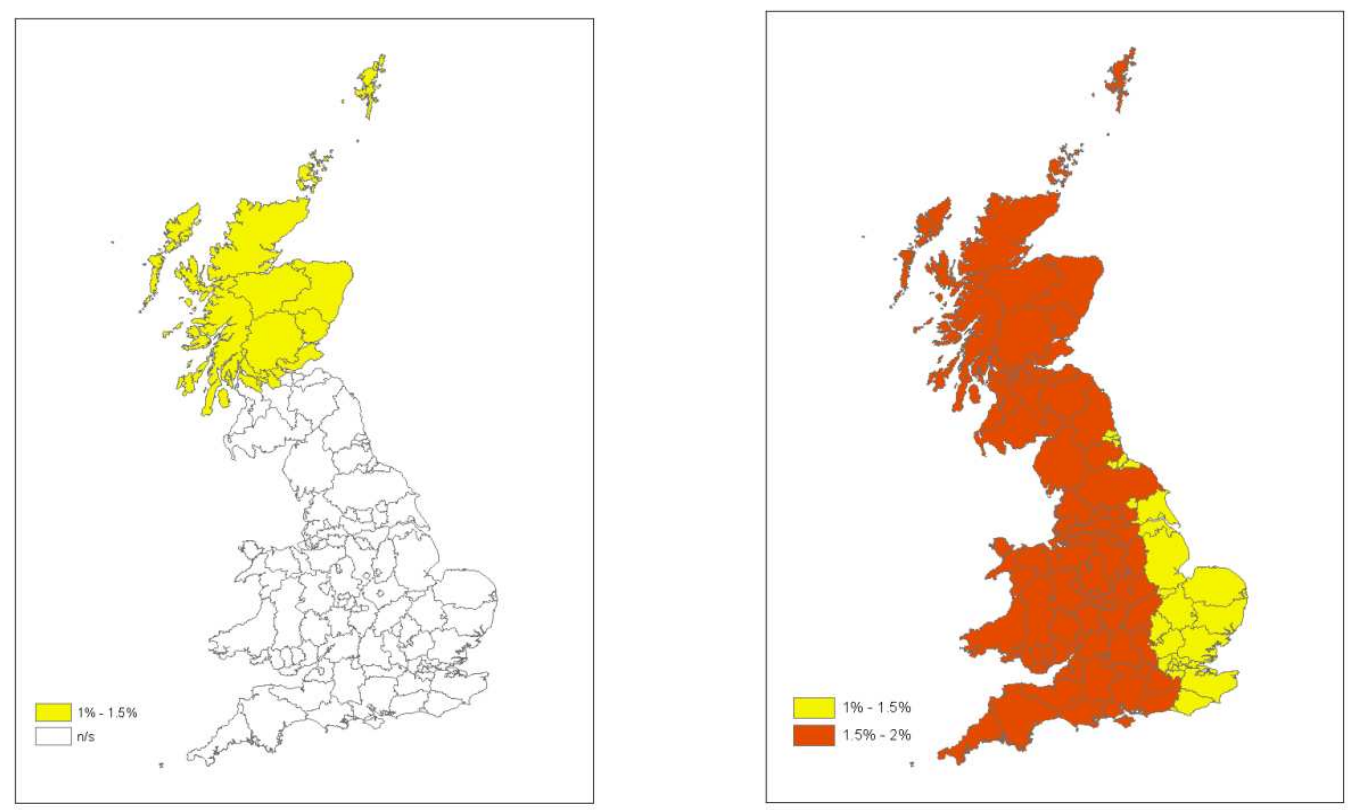

Note: All convergence speeds (shaded) correspond to significance levels of 5\% or less; n/s denotes "not significant". 


\begin{tabular}{|c|c|c|c|c|c|c|c|c|}
\hline \multicolumn{3}{|c|}{$\begin{array}{l}\text { Secondary Sector GVA per capita } \\
(2007 \mathrm{UK} £)\end{array}$} & \multicolumn{3}{|c|}{$\begin{array}{l}\text { Business Services and Finance } \\
\text { GVA per capita (2007 UK£) }\end{array}$} & \multicolumn{3}{|c|}{$\begin{array}{c}\text { Distribution, Transport and } \\
\text { Communication GVA per capita } \\
(2007 \text { UK£) }\end{array}$} \\
\hline & 1995 & 2007 & & 1995 & 2007 & & 1995 & 2007 \\
\hline Mean & 3,980 & 3,163 & Mean & $3,114.08$ & $5,186.98$ & Mean & $3,165.38$ & $4,049.26$ \\
\hline Median & 3,785 & 3,028 & Median & $2,408.89$ & $3,904.57$ & Median & $2,978.83$ & $3,761.01$ \\
\hline Maximum & 9,048 & 8,890 & Maximum & $34,661.66$ & $56,119.66$ & Maximum & $14,262.87$ & $13,583.81$ \\
\hline Minimum & 1,408 & 930 & Minimum & 905.50 & $1,485.23$ & Minimum & $1,459.05$ & $2,037.28$ \\
\hline Std. Dev. & 1,503 & 1,373 & Std. Dev. & $3,232.33$ & $5,417.09$ & Std. Dev. & $1,264.55$ & $1,360.99$ \\
\hline Growth (\%) & - & $-1.49 \%$ & Growth (\%) & - & $3.73 \%$ & Growth (\%) & - & $1.94 \%$ \\
\hline
\end{tabular}

Note: Growth (\%) refers to the average annual growth of GVA per capita across NUTS 3 regions over the period 1995-2007. The maximum and minimum for secondary sector average annual NUTS 3 growth are $2.51 \%$ and $-6.98 \%$, respectively. The equivalent figures for Business Services and Finance are $8.90 \%$ and $-0.17 \%$ respectively, and for Distribution, Transport and Communication the equivalent figures are $5.08 \%$ and $-0.48 \%$ respectively.

Table 2: Moran's I Global Spatial Autocorrelation Statistic

\begin{tabular}{|c|cc|cc|cc|}
\hline & \multicolumn{2}{|c|}{ Secondary } & $\begin{array}{c}\text { Business Services and } \\
\text { Finance }\end{array}$ & $\begin{array}{c}\text { Distribution, Transport and } \\
\text { Communication }\end{array}$ \\
\hline Spatial weights matrix & $W 1$ & $W 2$ & $W 1$ & $W 2$ & $W 1$ & $W 2$ \\
\hline Log real GVA per capita 1995 & $0.105^{* * *}$ & $0.137^{* * *}$ & $0.189^{* * *}$ & $0.219^{* * *}$ & $0.116^{* * *}$ & $0.138^{* * *}$ \\
Log real GVA per capita 2007 & $0.111^{* * *}$ & $0.109^{* * *}$ & $0.156^{* * *}$ & $0.210^{* * *}$ & $0.084^{* * *}$ & $0.148^{* * *}$ \\
GVA per capita Growth 1995-2007 & $0.051^{* *}$ & 0.015 & 0.012 & $0.045^{*}$ & -0.024 & 0.013 \\
\hline
\end{tabular}

Note: Significance at $* * * 1 \%, * * 5 \%$, and $* 10 \%$ level. Spatial weights matrices used in the above calculations are row standardised fixed distance $(W 1)$ and row standardised inverse distance (W2) matrices. Fixed distance threshold $(140 \mathrm{~km})$ selected using multi-distance spatial cluster analysis (Ripley's k-function). 
Table 3: Absolute Convergence Regressions for British NUTS 3 Sub-regions, 1995-2007

\begin{tabular}{|c|c|c|c|c|c|c|}
\hline \multicolumn{7}{|c|}{ Dependent variable: Average GVA Growth per Capita (1995-2007) } \\
\hline & \multicolumn{3}{|c|}{ Spatial Autoregressive Model (SAR) } & \multicolumn{3}{|c|}{ Spatial Error Model (SEM) } \\
\hline & Secondary & $\begin{array}{c}\text { Business } \\
\text { Services } \\
\text { and Finance }\end{array}$ & $\begin{array}{l}\text { Distribution, } \\
\text { Transport and } \\
\text { Communication }\end{array}$ & Secondary & $\begin{array}{c}\text { Business } \\
\text { Services } \\
\text { and Finance }\end{array}$ & $\begin{array}{l}\text { Distribution, } \\
\text { Transport and } \\
\text { Communication }\end{array}$ \\
\hline Constant & $\begin{array}{c}0.059 \\
(0.038)\end{array}$ & $\begin{array}{c}0.025 \\
(0.018)^{* *}\end{array}$ & $\begin{array}{c}0.132 \\
(0.026)^{* * *}\end{array}$ & $\begin{array}{c}0.071 \\
(0.040)^{*}\end{array}$ & $\begin{array}{c}0.029 \\
(0.022)^{* * *}\end{array}$ & $\begin{array}{c}0.135 \\
(0.026)^{* * *}\end{array}$ \\
\hline $\operatorname{lnGVA} 1995$ & $\begin{array}{c}-0.008 \\
(0.005)^{*}\end{array}$ & $\begin{array}{l}0.0003 \\
(0.003)\end{array}$ & $\begin{array}{c}-0.013 \\
(0.003)^{* * *}\end{array}$ & $\begin{array}{c}-0.011 \\
(0.005)^{* *}\end{array}$ & $\begin{array}{c}0.001 \\
(0.002)\end{array}$ & $\begin{array}{c}-0.014 \\
(0.003)^{* * *}\end{array}$ \\
\hline$\rho(\mathrm{SAR})$ & $\begin{array}{c}0.57 \\
(0.126)^{* * *}\end{array}$ & $\begin{array}{c}0.284 \\
(0.176)\end{array}$ & $\begin{array}{c}-0.454 \\
(0.220)^{* *}\end{array}$ & & & \\
\hline$\tau(\mathrm{SEM})$ & & & & $\begin{array}{c}0.824 \\
(0.083)^{* * * *}\end{array}$ & $\begin{array}{c}0.208 \\
(0.249)\end{array}$ & $\begin{array}{c}0.253 \\
(0.241)\end{array}$ \\
\hline $\mathrm{R}^{2}$ & 0.05 & 0.01 & 0.14 & 0.06 & 0.01 & 0.13 \\
\hline Log Likelihood & 313.851 & 336.07 & 396.02 & 314.73 & 335.53 & 395.03 \\
\hline Number of Obs & 125 & 125 & 125 & 125 & 125 & 125 \\
\hline
\end{tabular}

Note: Standard errors are given in parenthesis. Significance at $* * * 1 \%, * * 5 \%$, and $* 10 \%$ level 
Table 4: Conditional Convergence Regressions for British NUTS 3 Sub-regions, 1995-2007

\begin{tabular}{|c|c|c|c|c|c|c|}
\hline \multicolumn{7}{|c|}{ Dependent variable: Average GVA Growth per Capita (1995-2007) } \\
\hline & \multicolumn{3}{|c|}{ Spatial Autoregressive Model (SAR) } & \multicolumn{3}{|c|}{ Spatial Error Model (SEM) } \\
\hline \multirow[b]{2}{*}{ constant } & Secondary & $\begin{array}{l}\text { Business } \\
\text { Services and } \\
\text { Finance }\end{array}$ & $\begin{array}{c}\text { Distribution, } \\
\text { Transport and } \\
\text { Communication }\end{array}$ & Secondary & $\begin{array}{l}\text { Business } \\
\text { Services and } \\
\text { Finance }\end{array}$ & $\begin{array}{c}\text { Distribution, } \\
\text { Transport and } \\
\text { Communication }\end{array}$ \\
\hline & $\begin{array}{l}-0.013 \\
(0.054)\end{array}$ & $\begin{array}{c}-0.077 \\
(0.038)\end{array}$ & $\begin{array}{c}0.119 \\
(0.034) * * *\end{array}$ & $\begin{array}{l}-0.015 \\
-0.060)\end{array}$ & $\begin{array}{l}-0.032 \\
0.037)\end{array}$ & $\begin{array}{c}0.135 \\
0 * *\end{array}$ \\
\hline \multirow[t]{2}{*}{$\operatorname{lnGVA}_{1995}$} & -0.012 & 0.003 & -0.016 & -0.014 & 0.003 & -0.018 \\
\hline & $(0.005)^{* *}$ & $(0.004)$ & $(0.004) * * *$ & $(0.005)^{* *}$ & (0.004) & $(0.004) * * *$ \\
\hline \multirow[t]{2}{*}{ Grades } & 0.0002 & 0.000 & 0.0001 & 0.001 & 0.000 & 0.000 \\
\hline & $(0.001)$ & $(0.001)$ & $(0.0004)$ & $(0.001)$ & $(0.001)$ & $(0.000)$ \\
\hline \multirow[t]{2}{*}{ Pupil_Teacher } & 0.002 & 0.004 & 0.001 & 0.003 & 0.003 & 0.000 \\
\hline & $(0.001)^{*}$ & $(0.001) * * *$ & $(0.001)$ & $(0.002)^{* *}$ & $(0.001) * * *$ & $(0.001)$ \\
\hline \multirow[t]{2}{*}{ Agri } & 0.180 & 0.003 & -0.143 & 0.230 & -0.006 & -0.173 \\
\hline & $(0.144)$ & $(0.130)$ & $(0.074)^{*}$ & $(0.146)$ & $(0.128)$ & $(0.074)^{* *}$ \\
\hline \multirow[t]{2}{*}{ No. of Businesses } & 0.263 & -0.368 & 0.294 & -0.611 & -0.379 & 0.329 \\
\hline & $(1.141)$ & $(0.318)$ & $(0.187)$ & (1.093) & $(0.326)$ & $(0.198)^{*}$ \\
\hline \multirow[t]{2}{*}{ Capital Expenditure } & 0.102 & 0.067 & 0.173 & 0.129 & 0.088 & 0.186 \\
\hline & $(0.206)$ & $(0.176)$ & $(0.106)$ & (0.199) & $(0.176)$ & $(0.108)^{*}$ \\
\hline \multirow[t]{2}{*}{ Female Emp'ment } & 0.001 & 0.001 & 0.001 & 0.001 & 0.001 & 0.001 \\
\hline & $(0.001)$ & $(0.001)$ & $(0.0004)^{* *}$ & $(0.001)$ & $(0.001)$ & $(0.0004)^{* * *}$ \\
\hline \multirow[t]{2}{*}{$\mathrm{NE}$} & 0.005 & -0.013 & -0.010 & 0.008 & -0.010 & -0.005 \\
\hline & $(0.010)$ & $(0.009)$ & $(0.005)^{*}$ & $(0.019)$ & $(0.007)$ & $(0.004)$ \\
\hline \multirow[t]{2}{*}{ NW } & -0.003 & -0.008 & -0.008 & -0.002 & -0.006 & -0.007 \\
\hline & $(0.008)$ & $(0.007)$ & $(0.004)^{* *}$ & $(0.015)$ & $(0.006)$ & $(0.004) * *$ \\
\hline \multirow[t]{2}{*}{ YH } & 0.008 & -0.004 & -0.008 & 0.008 & -0.005 & -0.005 \\
\hline & $(0.009)$ & $(0.007)$ & $(0.004)^{*}$ & $(0.012)$ & $(0.006)$ & $(0.004)$ \\
\hline \multirow[t]{2}{*}{ EM } & 0.009 & 0.001 & -0.002 & 0.007 & 0.003 & -0.0003 \\
\hline & $(0.009)$ & $(0.008)$ & $(0.005)$ & $(0.012)$ & $(0.007)$ & $(0.004)$ \\
\hline \multirow[t]{2}{*}{ WM } & -0.001 & -0.005 & -0.001 & -0.001 & -0.002 & -0.0002 \\
\hline & $(0.008)$ & $(0.007)$ & $(0.004)$ & $(0.012)$ & $(0.006)$ & $(0.004)$ \\
\hline \multirow[t]{2}{*}{$\mathrm{SE}$} & -0.0002 & -0.006 & -0.003 & 0.001 & -0.005 & -0.002 \\
\hline & $(0.008)$ & $(0.007)$ & $(0.004)$ & $(0.009)$ & $(0.006)$ & $(0.003)$ \\
\hline \multirow[t]{2}{*}{$\mathrm{L}$} & -0.009 & 0.0002 & -0.010 & -0.006 & 0.0003 & -0.011 \\
\hline & $(0.011)$ & $(0.010)$ & $(0.006)$ & $(0.011)$ & $(0.010)$ & $(0.006)^{*}$ \\
\hline \multirow[t]{2}{*}{ SW } & 0.004 & -0.005 & -0.002 & 0.012 & -0.002 & -0.001 \\
\hline & $(0.008)$ & $(0.007)$ & $(0.004)$ & $(0.012)$ & $(0.005)$ & $(0.003)$ \\
\hline \multirow[t]{2}{*}{$\mathrm{W}$} & 0.005 & -0.003 & -0.0002 & 0.008 & -0.001 & -0.002 \\
\hline & $(0.009)$ & $(0.008)$ & $(0.005)$ & $(0.014)$ & $(0.007)$ & $(0.005)$ \\
\hline \multirow[t]{2}{*}{$\mathrm{S}$} & 0.018 & 0.015 & -0.0001 & 0.022 & 0.014 & -0.004 \\
\hline & $(0.010)^{*}$ & $(0.008)^{*}$ & $(0.005)$ & $(0.027)$ & $(0.006)^{* *}$ & $(0.004)$ \\
\hline \multirow[t]{2}{*}{$\rho(\mathrm{SAR})$} & 0.275 & -0.339 & -0.869 & & & \\
\hline & $(0.228)$ & $(0.210)$ & $(0.239)^{* * *}$ & & & \\
\hline$\tau(\mathrm{SEM})$ & & & & 0.939 & -0.936 & -0.989 \\
\hline & & & & $(0.035)^{* * *}$ & $(0.327)^{* * *}$ & $(0.323)^{* * *}$ \\
\hline $\mathrm{R}^{2}$ & 0.18 & 0.12 & 0.28 & 0.19 & 0.17 & 0.31 \\
\hline Log Likelihood & 323.25 & 343.56 & 407.42 & 323.98 & 347.39 & 409.32 \\
\hline Number of Obs & 125 & 125 & 125 & 125 & 125 & 125 \\
\hline
\end{tabular}

Note: Standard errors are given in parenthesis. Significance at $* * * 1 \%$, **5\%, and $* 10 \%$ level. The NUTS 1 level regional dummy variables included are North East (NE), North West (NW), Yorkshire and the Humber (YH), East Midlands (EM), West Midlands (WM), South East (SE), London (L), South West (SW), Wales (W), and Scotland (S). East England is the base region. 
Table 5: Secondary Sector local GWR and global SAR and SEM parameter estimates

\begin{tabular}{|c|c|c|c|c|c|c|c|}
\hline \multicolumn{8}{|c|}{ Dependent variable: Average Secondary GVA Growth per Capita (1995-2007) } \\
\hline & Min & $\begin{array}{l}\text { Lower } \\
\text { Quartile }\end{array}$ & Median & $\begin{array}{l}\text { Upper } \\
\text { Quartile } \\
\end{array}$ & Max & $\begin{array}{l}\text { Global } \\
\text { SAR }\end{array}$ & $\begin{array}{l}\text { Global } \\
\text { SEM } \\
\end{array}$ \\
\hline constant & -0.099 & -0.094 & -0.085 & -0.061 & 0.052 & -0.013 & -0.015 \\
\hline $\operatorname{lnGVA}_{1995}$ & -0.017 & -0.005 & -0.003 & -0.003 & -0.002 & $-0.012 * *$ & $-0.014 * *$ \\
\hline Grades & 0.000 & 0.000 & 0.000 & 0.000 & 0.001 & 0.000 & 0.001 \\
\hline Pupil_Teacher & 0.000 & 0.001 & 0.002 & 0.003 & 0.003 & $0.002 *$ & $0.003^{*}$ \\
\hline No. of Businesses & -2.481 & -1.863 & -1.347 & -1.083 & 0.572 & 0.263 & -0.611 \\
\hline Capital Expenditure & -0.140 & -0.108 & -0.061 & 0.082 & 0.292 & 0.102 & 0.110 \\
\hline Female Emp'ment & 0.000 & 0.001 & 0.001 & 0.002 & 0.002 & 0.001 & 0.001 \\
\hline Agri & 0.183 & 0.300 & 0.314 & 0.331 & 0.391 & 0.180 & 0.230 \\
\hline $\mathrm{R}^{2}$ & 0.14 & 0.14 & 0.14 & 0.26 & 0.26 & 0.18 & 0.19 \\
\hline
\end{tabular}

Note: Significance indicated for global parameters only. Figure 5 illustrates significance of local parameters. Significance of global parameters denoted as follows: ***1\%, **5\%, and *10\% level. SAR and SEM global parameter estimates are extracted from Table 4 above.

Table 6: Business Services and Finance GWR and global SAR and SEM parameter estimates

\begin{tabular}{|c|c|c|c|c|c|c|c|}
\hline \multicolumn{8}{|c|}{ Dependent variable: Average Business Services and Finance GVA Growth per Capita (1995-2007) } \\
\hline & Min & $\begin{array}{l}\text { Lower } \\
\text { Quartile }\end{array}$ & Median & $\begin{array}{l}\text { Upper } \\
\text { Quartile }\end{array}$ & Max & $\begin{array}{l}\text { Global } \\
\text { SAR }\end{array}$ & $\begin{array}{l}\text { Global } \\
\text { SEM }\end{array}$ \\
\hline constant & -0.045 & -0.034 & -0.032 & -0.030 & 0.026 & $-0.077 *$ & -0.083 \\
\hline $\operatorname{lnGVA}_{1995}$ & 0.001 & 0.002 & 0.002 & 0.002 & 0.003 & 0.003 & 0.003 \\
\hline Grades & 0.000 & 0.000 & 0.000 & 0.000 & 0.001 & 0.000 & 0.000 \\
\hline Pupil_Teacher & 0.001 & 0.001 & 0.001 & 0.001 & 0.002 & $0.004 * * *$ & $0.003 * * *$ \\
\hline No. of Businesses & -0.941 & -0.511 & -0.314 & -0.269 & -0.243 & -0.368 & -0.379 \\
\hline Capital Expenditure & 0.025 & 0.047 & 0.067 & 0.106 & 0.203 & 0.067 & 0.088 \\
\hline Female Emp'ment & 0.000 & 0.001 & 0.001 & 0.001 & 0.001 & 0.001 & 0.001 \\
\hline Agri & -0.020 & 0.004 & 0.010 & 0.021 & 0.030 & 0.024 & -0.006 \\
\hline $\mathrm{R}^{2}$ & 0.07 & 0.07 & 0.08 & 0.18 & 0.18 & 0.12 & 0.17 \\
\hline
\end{tabular}

Note: Significance indicated for global parameters only. Significance of global parameters denoted as follows: $* * * 1 \%, * * 5 \%$, and $* 10 \%$ level. 
Table 7: Distribution, Transport and Communications GWR and global SAR and SEM parameter estimates

\begin{tabular}{|c|c|c|c|c|c|c|c|}
\hline $\begin{array}{l}\text { Dependent variable } \\
\text { (1995-2007) }\end{array}$ & & & $s p$ & on & $n$ & Gro & pita \\
\hline & Min & $\begin{array}{l}\text { Lower } \\
\text { Quartile }\end{array}$ & Median & $\begin{array}{l}\text { Upper } \\
\text { Quartile }\end{array}$ & Max & $\begin{array}{l}\text { Global } \\
\text { SAR }\end{array}$ & $\begin{array}{l}\text { Global } \\
\text { SEM }\end{array}$ \\
\hline constant & 0.089 & 0.099 & 0.110 & 0.122 & 0.157 & $0.119 * * *$ & $0.135 * * *$ \\
\hline $\operatorname{lnGVA}_{1995}$ & -0.020 & -0.018 & -0.017 & -0.017 & -0.016 & $-0.016 * * *$ & $-0.018 * * *$ \\
\hline Grades & 0.000 & 0.000 & 0.000 & 0.000 & 0.001 & 0.000 & 0.000 \\
\hline Pupil_Teacher & -0.001 & 0.000 & 0.000 & 0.001 & 0.001 & 0.001 & 0.000 \\
\hline No. of Businesses & 0.042 & 0.083 & 0.118 & 0.170 & 0.264 & 0.294 & $0.329 *$ \\
\hline Capital Expenditure & 0.051 & 0.081 & 0.090 & 0.996 & 0.153 & 0.173 & $0.186^{*}$ \\
\hline Female Emp'ment & 0.000 & 0.001 & 0.001 & 0.002 & 0.002 & $0.001 * *$ & $0.001 * * *$ \\
\hline Agri & -0.180 & -0.122 & -0.097 & -0.087 & 0.062 & $-0.144 *$ & $-0.173 * *$ \\
\hline $\mathrm{R}^{2}$ & 0.20 & 0.23 & 0.25 & 0.29 & 0.29 & 0.28 & 0.31 \\
\hline
\end{tabular}

Note: Significance indicated for global parameters only. Figure 5 illustrates significance of local parameters. Significance of global parameters denoted as follows: $* * * 1 \%, * * 5 \%$, and $* 10 \%$ level. 